\title{
Drought tolerant maize for farmer adaptation to drought in sub-Saharan Africa: Determinants of adoption in eastern and southern Africa
}

\author{
Monica Fisher ${ }^{1} \cdot$ Tsedeke Abate $^{2}$. \\ Rodney W. Lunduka ${ }^{3}$. Woinishet Asnake ${ }^{4}$. \\ Yoseph Alemayehu ${ }^{4} \cdot$ Ruth B. Madulu ${ }^{5}$
}

Received: 23 February 2015 / Accepted: 19 June 2015 /Published online: 4 July 2015

(C) The Author(s) 2015. This article is published with open access at Springerlink.com

\begin{abstract}
In sub-Saharan Africa (SSA), "maize is life," due to its importance to food security and economic wellbeing. Around $40 \%$ of Africa's maize-growing area faces occasional drought stress, resulting in yield losses of 10-25\%. Around $25 \%$ of the maize crop suffers frequent drought, with losses of up to half the harvest. To reduce vulnerability and improve food security, the Drought Tolerant Maize for Africa (DTMA) project has made releases of 160 drought tolerant (DT) maize varieties between 2007 and 2013. These have been tested in experimental and farmers' fields, and disseminated to farmers in 13 African countries through national agricultural research systems and private seed companies. Yields of the new varieties are superior to those of currently available commercial maize varieties under both stress and optimum growing conditions. Although the benefits of DT maize for African farmers have been repeatedly predicted, realization of those benefits depends on farmer uptake, which has received limited empirical study. We use new plot-level data from surveys of 3,700 farm households in six countries (Ethiopia, Tanzania, Uganda, Malawi, Zambia, and Zimbabwe) to measure DT maize adoption rates and their determinants. The data reveal considerable inter-
\end{abstract}

Electronic supplementary material The online version of this article (doi:10.1007/s10584-015-1459-2) contains supplementary material, which is available to authorized users.

Monica Fisher

monica.fisher@oregonstate.edu

1 Applied Economics Department, 213 Ballard Extension Hall, Oregon State University, Corvallis, OR 97331, USA

2 CIMMYT-Kenya, ICRAF House United Nations Avenue, Gigiri Village Market-00621, PO Box 1041, Nairobi, Kenya

3 CIMMYT- Southern Africa Regional Office (SARO), PO Box MP 163, Mount Pleasant Harare, Zimbabwe

4 CIMMYT-Ethiopia, PO Box 5689, Addis Ababa, Ethiopia

5 Mikocheni Agricultural Research Institute, PO Box 6226, Dar Es Salaam, Tanzania 
country variation in farmer uptake of DT maize, from $9 \%$ of maize plots in Zimbabwe to $61 \%$ in Malawi. The major barriers to adoption include unavailability of improved seed, inadequate information, lack of resources, high seed price, and perceived attributes of different varieties. Based on the results, we recommend that seed companies and agro-dealers ensure adequate supply of DT maize seed in local markets and sell seed in affordable micro-packs ( 1 or $2 \mathrm{~kg}$ ). Furthermore, the DTMA project and partners should ramp up promotional efforts to ensure widespread awareness and understanding of the benefits of the new DT maize varieties.

\section{Introduction}

Agricultural development in sub-Saharan Africa (SSA) faces unprecedented challenges, due to changes in demand for food, market conditions, and climate. The Intergovernmental Panel on Climate Change (IPCC 2014) predicts that, under medium scenarios, mean annual temperature over extensive areas of Africa will be $2{ }^{\circ} \mathrm{C}$ higher during the middle of the 21 st Century than during the late 20th Century. Despite uncertainty about future changes in rainfall in SSA (IPCC 2014), climate change models consistently predict increased incidence of drought (Li et al. 2009). Increasing temperatures and changes in precipitation are expected to adversely affect biodiversity, amplify existing stress on water supplies, exacerbate the vulnerability of agricultural systems, and increase the burden of a range of climate-related health outcomes (IPCC 2014).

African farmers are not helpless in the face of variable and changing climates; they already adapt to climate variability and change in a multiplicity of ways (e.g., Thomas et al. 2007; Deressa et al. 2009). However, in some parts of SSA, the magnitude and speed of the predicted changes are likely to outstrip the local efforts to manage those changes, and large public and private investments in crop breeding, irrigation infrastructure, safety nets (e.g., micro-insurance), processing/marketing infrastructure, and storage facilities are needed to meet the food needs of the growing human population (Burke and Lobell 2010).

This paper focuses on recent advances in maize research that hold promise for helping African farmers adapt to drought. Maize is the most important food crop in SSA, where it is almost completely rainfed and, therefore, dependent on the region's increasingly erratic precipitation. Around $40 \%$ of Africa's maize-growing area faces occasional drought stress in which yield losses are 10-25\%. Around $25 \%$ of the maize crop suffers frequent drought, with losses of up to half the harvest (CIMMYT 2013). To reduce vulnerability and improve food security, the Drought Tolerant Maize for Africa (DTMA) project has made releases of 160 drought tolerant (DT) maize varieties, between 2007 and 2013.

The DT maize varieties have been bred using modern conventional methods, without genetic modification. In addition to drought tolerance, the varieties have other attractive traits, such as resistance to major diseases and high protein content. The DT maize varieties have similar labor requirements and seed costs as non-DT commercial varieties. Importantly, some of the DT maize varieties are also nitrogen use efficient. Although the switch from local to improved maize can be a catalyst for increasing farmers' use of other inputs, especially fertilizer, many Africa farmers grow improved maize varieties without fertilizer (Smale et al. 2011).

The new DT maize varieties underwent extensive multi-location on-farm testing using a participatory variety selection approach with farmers. On-farm trials across sites in eastern and southern Africa revealed that DT maize varieties out-yield popular commercial checks by $83-$ 
$137 \%$ (controlled drought), 26-47\% (random drought), and 25-56\% (optimal rainfall conditions) (Unpublished data from Tsedeke Abate, DTMA project Leader, March 2015). The yield advantage of the new DT maize varieties over local maize varieties should be even greater. Research in SSA has indicated a consistent yield advantage of improved maize varieties over local maize varieties at different levels of fertilizer use and various soil fertility and rainfall conditions (Smale and Jayne 2003).

Across the 13 DTMA countries (Angola, Benin, Ethiopia, Ghana, Kenya, Malawi, Mali, Mozambique, Nigeria, Tanzania, Uganda, Zambia, and Zimbabwe) seed delivery has been the responsibility of national agricultural research systems and public and private seed companies. To diffuse information on the new DT varieties, the DTMA project has used field demonstrations and field days. Messages have been channeled via posters, radio and television broadcasts, and newspapers. In 2013 alone, more than 33,000 MT of seed had been delivered to farmers in the 13 SSA countries (CIMMYT 2014).

A recent assessment of DT maize adoption in Africa, based on the economic surplus method, predicted large positive impacts of increasing average yields and reducing yield variability (La Rovere et al. 2014). And by decreasing the vulnerability of farm households to drought-related harvest failure, DT varieties also reduce the need for harmful post-failure coping strategies, such as borrowing, reducing food consumption, sale of household assets, or taking children out of school.

Although the benefits of DT maize for African farmers have been repeatedly predicted, realization of those benefits depends on adoption of the new DT maize varieties by SSA farmers, which has only been studied for 200 farm households in Nigeria (Tambo and Abdoulaye 2013). The Nigeria study suggests considerable farmer demand for DT varieties, but the literature on adoption of modern crop varieties by smallholders in SSA indicates an uneven record: incidents of widespread adoption (Alene et al. 2009) are mixed with examples of low rates of adoption and lack of sustained use of seemingly advantageous farm technologies (Kijima et al. 2011). Furthermore, studies indicate that smallholder farmers in SSA are generally aware of local environmental changes, but many have made no adjustments to reduce impacts of increasing temperature and/or decreasing precipitation (Fosu-Mensah et al. 2012; Gbetibouo et al. 2010). Research is needed to uncover factors that encourage farmer adaptation.

This study evaluates prospects for widespread adoption of DT maize in SSA, by measuring adoption levels and determinants in three countries in eastern Africa (Ethiopia, Tanzania, and Uganda) and three countries in southern Africa (Malawi, Zambia, and Zimbabwe). The six countries together account for one-third of maize area and maize production in SSA (calculated from FAOSTAT 2014 data). In these countries, maize is important for food security, drought risk exhibits spatial variability, and DT maize adoption has potential to bring about substantial reduction in food insecurity. Figures S1 and S2 of Online Resource 1 show the distribution of maize mega-environment (MME) and failed season drought probability across the six study countries. It is important to point out, however, that the new DT maize varieties are high yielding across a range of MMEs and under both moderate drought and good rainfall conditions (Unpublished data from Tsedeke Abate, DTMA project Leader, May 2015). In this paper, we seek to identify future investments that will stimulate DT maize adoption and thereby increase farmer resilience to drought in SSA. (Detailed information about the DT maize varieties that have been released in the six study countries are provided in Table S1 of Online Resource 2.) 


\section{Agricultural adaptation by smallholder farmers in response to climate variability and change}

Recent studies have examined the response of African farmers to extreme weather events and their attempts to adapt to perceived long-term environmental changes. We here review 19 relevant empirical studies, published in scholarly journals, covering 14 SSA countries and over 16,000 farmers (Thomas et al. 2007; Hassan and Nhemachena 2008; Barbier et al. 2009; Bryan et al. 2009; Deressa et al. 2009; Mertz et al. 2009; Gbetibouo et al. 2010; Orlove et al. 2010; Cavatassi et al. 2011; Codjoe et al. 2012; Hisali et al. 2011; Sofoluwe et al. 2011; FosuMensah et al. 2012; Bryan et al. 2013; Tambo and Abdoulaye 2013; Bele et al. 2014; Brooks 2014; Fisher and Snapp 2014; Westengen and Brysting 2014). Results of reviewed studies are used to address two questions. First, do smallholder farmers in SSA perceive climate as variable or changing? Clearly, adaptation will not be attempted, if farmers do not recognize climate change (Burke and Lobell 2010). Second, what adjustments in agricultural practice have African farmers used to adapt to climate variability and change?

\subsection{Do smallholder farmers in SSA perceive climate variability and change?}

Most of the reviewed studies included survey questions to gauge farmers' perceptions about climate variability and change. The usual approach was to ask farmers one or more open-ended questions about whether they had noticed any long-term changes (e.g., Bryan et al. 2009). Another approach was to ask farmers to rank the severity of impacts on agriculture from various sources (e.g., Westengen and Brysting 2014). In a third approach, Hisali et al. (2011) used results of the 2005/06 Uganda National Household Survey, in which farmers reported the severity, frequency, and duration of major climatic events during the previous 5 years.

Overall, results of the studies indicate farmers from the 14 surveyed countries generally do perceive that average temperature has increased and average rainfall has decreased over the last few decades. For example, 86 and $64 \%$ of respondents surveyed in Ethiopia and South Africa, respectively, reported that temperature has increased, while 65 and $79 \%$ observed that rainfall has declined (Bryan et al. 2009). Farmers in several countries reported changes in the onset, duration, and predictability of the rainy season, and increased drought frequency (Hassan and Nhemachena 2008; Bele et al. 2014; Fisher and Snapp 2014). Ugandan farmers reported an increasing number of droughts and other climate-related events, and half of sampled farmers reported that, during the past 5 years, droughts typically lasted five months or longer (Hisali et al. 2011). Farmers' perceptions of climate variability and change differed among regions of a country, as well as with gender, type of farming (e.g., livestock vs. crops), and occupation (Thomas et al. 2007; Codjoe et al. 2012).

\subsection{Adjustments in agricultural practices by smallholder farmers in response to climate variability and change}

The reviewed studies found smallholder farmers in SSA have used a variety of agricultural adaptations. Some adaptations, such as change in planting date, switching crop species, crop diversification, and soil and water conservation, have been widely used. Other adaptations, such as expanded irrigation, weather insurance, and switching crop varieties, have not been widely used, but are likely to become more important in the future. 


\subsubsection{Change in planting dates}

Changing planting dates is relatively inexpensive and easy to implement, and is particularly important for farmers in rainfed systems. The onset of the rainy season is crucial to the timing of rainfed crops: if a farmer plants too early, soil moisture will be insufficient for seed germination; if a farmer plants too late, intense rain might wash seed away (Reason et al. 2005). Farmers in several SSA countries reported they shift crop planting dates in response to year-to-year variability in rainy season onset (Fosu-Mensah et al. 2012; Bryan et al. 2013; Sofoluwe et al. 2011; Bele et al. 2014). The main limitation is availability of accessible and accurate climate forecasts, which complement indigenous knowledge. Female farmers in the Afram Plains of Ghana highlighted the importance of seasonal forecasts in choosing which crops to plant and when (Codjoe et al. 2012). Ugandan farmers indicated that forecasts from the Ugandan Department of Meteorology, along with their own knowledge and observations, helped them decide whether or not to plant slower maturing crops for a particular season (Orlove et al. 2010).

\subsubsection{Switching crop species}

Climate change will likely affect regional cropping patterns in SSA (Kurukulasuriya and Mendelsohn 2006). In 14 of the 19 studies, farmers reported they reassessed and cultivated different crops in response to perceived changes in temperature and rainfall. For example, Kenyan farmers switched to cassava, sweet potatoes, and pigeon peas (Bryan et al. 2013). Cassava, in particular, is potentially useful for adaptation to climate change in SSA, because it grows in marginal soils, tolerates periodic and extended periods of drought and heat, and is left in the ground until needed (Jarvis et al. 2012). Malawian farmers migrated to cassava growing areas during the 2001/02 famine (Brooks 2014). Important factors enabling crop switching are access to irrigation and to extension information (Bryan et al. 2009, 2013).

\subsubsection{Crop diversification}

Many farmer adaptations to climate variability center on diversification to take advantage of the differential effects that a given climate event or condition might have on different crops and activities during the year. For example, in rainfed systems that are prone to drought, diversification of farm plot locations can take advantage of spatial variability in rainfall. The most common diversification strategy identified by the reviewed studies was to grow a variety of crops (Bryan et al. 2009, 2013; Bele et al. 2014; Westengen and Brysting 2014). Previous research demonstrated a positive correlation between crop diversity and production (Di Falco et al. 2010). The likelihood farmers will diversify their crops is positively influenced by secure land tenure, access to information and credit, labor supply, and farming experience (Hassan and Nhemachena 2008; Gbetibouo et al. 2010; Fosu-Mensah et al. 2012).

\subsubsection{Soil and water conservation}

Soil and water conservation (SWC) is important for alleviating water shortages, worsening soil conditions, and other negative effects of climate variability and change (Kurukulasuriya and Mendelsohn 2006). The reviewed studies found that farmers applied SWC approaches for various reasons, including adaptation to environmental change. In Ghana, female farmers in 
particular used rainwater harvesting from roofs or other man-made structures as an adaptation to drought (Codjoe et al. 2012). Farmers in Burkina Faso, used a number of SWC techniques building stone boundaries around fields, micro water-harvesting, and soil restoration - to increase production in years of good rainfall and reduce production variability during droughts (Barbier et al. 2009). Use of SWC approaches depends on household size (the techniques are labor intensive), farming experience, education, farm size, and credit access (Deressa et al. 2009; Bryan et al. 2013).

\subsubsection{Small- and large-scale irrigation}

Only $6 \%$ of total cultivated area in SSA is currently irrigated, and that is concentrated mostly in five countries. However, the introduction of irrigation into rainfed cropping systems will be critical to future agricultural production in some regions, and is predicted to be a profitable investment on both small and large scales (You et al. 2011). Irrigation increases yields and returns on investments in farm inputs; it also allows farmers flexibility in planting dates, crop species and varieties, and length or number of growing seasons (Burke and Lobell 2010).

Although farmers surveyed in the reviewed studies frequently mentioned irrigation as a preferred adaptation, few practiced irrigation. Irrigation was common only in Burkina Faso, where government and non-governmental organizations have invested in sophisticated irrigation canals, and have built more than 1,400 small dams since the 1970s drought (Barbier et al. 2009). Use of irrigation is constrained by limited access to or availability of water sources, poor water management, lack of capital for investment in irrigation technology, small farm size, and high labor requirements (Barbier et al. 2009; Deressa et al. 2009; Sofoluwe et al. 2011).

\subsubsection{Micro-insurance}

The adaptation strategies commonly used by smallholder farmers in SSA, such as shifting planting date and crop diversification, often fail in years of very poor rainfall, even when used in combination. Micro-insurance, particularly index-based insurance, might improve the capacity of farmers to adapt to climate change, but has not been widely implemented in SSA, and was not used by any farmers in the reviewed studies. The challenges of microinsurance include high cost and logistical difficulties of getting the products to farmers, and the need to reflect diverse weather events and production conditions (Lybbert and Sumner 2012).

\subsubsection{Switching crop varieties}

Switching to crop varieties less sensitive to climatic stress is one of the preferred strategies of farmers in SSA. Policymakers also support this approach: a UN General Assembly resolution in 2009 emphasized development of crop varieties that tolerate environmental stresses, including drought (Westengen and Brysting 2014). New varieties of staple crops, many still under development, provide drought and heat tolerance, as well as early maturation (Cairns et al. 2013; Karaba et al. 2007). The reviewed studies reveal that improved short-season varieties were available and farmers were growing them to escape drought (Thomas et al. 2007; Fosu-Mensah et al. 2012; Fisher and Snapp 2014; Westengen and Brysting 2014). However, while farmers expressed demand for drought tolerance, availability of improved DT maize and sorghum seed limited its use in several countries (Cavatassi et al. 2011; Fisher and Snapp 2014; Westengen and Brysting 2014). Only in Nigeria did farmers have access to 
improved DT varieties due to presence of two development projects (Tambo and Abdoulaye 2013).

\subsection{Contributions of the present study}

The 19 reviewed studies reveal many agricultural adaptations used by smallholder farmers in SSA. Yet for many farmers these methods are insufficient for protecting livelihoods in drought prone regions of SSA (Shiferaw et al. 2014). Investments by governments and other institutions in development of new crop varieties, irrigation infrastructure, micro-insurance, processing/marketing infrastructure, and storage facilities will likely be necessary (Burke and Lobell 2010). Our study focuses on the development and promotion of new varieties of DT modern maize. This agricultural adaptation is low-cost and relatively easy for farmers to use, but development of these improved varieties relies on considerable private and public investment. We measure adoption levels and examine factors that influence uptake by farmers in six SSA countries to evaluate prospects for widespread adoption in SSA.

\section{Study context and data}

\subsection{The household survey}

DTMA adoption surveys were conducted in the 13 DTMA countries, during 2013. Data for this study come from six countries: Ethiopia, Tanzania, and Uganda in eastern Africa; Malawi, Zambia, and Zimbabwe in southern Africa. Data for Benin, Ghana, Mali, Mozambique, and Nigeria were not yet available; data for Kenya and Angola were excluded, due to very low adoption rates, which precluded assessment of adoption determinants.

Sample sizes for the six surveys ranged from 400 to 900 farm households, depending on the area of maize cultivation. Sample selection was done in four stages. The first two stages were purposive. First, the main geographic areas where significant dissemination of DTMA seed had occurred were targeted in each country. Second, four to nine districts were selected within each target area, particularly districts where significant DT maize dissemination had occurred. The next two sampling stages were random. Ten villages were randomly selected in each selected district. Then, ten maize-farming households in each sampled village were randomly selected. Farm interviews, using a five page questionnaire, were conducted in 2013. The household head was interviewed, with the spouse joining where possible. Information collected concerned household demographics and socio-economic status, agricultural landholding, agricultural input use for maize production, maize varieties cultivated, and awareness of and demand for DT maize varieties. The short questionnaire, experienced enumerators, and close supervision by the study's authors ensured collection of high quality data.

\subsection{Descriptive statistics of the study households}

Average age of household heads ranged from 40 to 53 years in the six countries (Table 1). Zimbabwe had the highest percentage of households headed by females (27\%); Uganda had the lowest ( $8 \%$ ). Household heads in Zimbabwe had the highest educational level (mean= 7.5 years of schooling); Ethiopians had the lowest (3.2 years). Labor availability, measured as 
the number of household members, ranged from an average of 5.6 in Malawi to 7.6 in Ethiopia.

Tanzanian farm households had the largest cultivated area (4.6 acres), and Malawian households the smallest (2.2 acres). Tropical livestock units (TLU) were calculated, using the approach of Jahnke (1982) to weight different categories of livestock. Mean number of TLU was highest in Ethiopian households, and five times lower in Malawian households.

Households were asked about maize self-sufficiency during the last agricultural year. Ugandan households had the highest maize self-sufficiency (64\%), and Malawian households the lowest (18\%). Households were also asked the likelihood of accessing credit to buy maize inputs. Tanzanian households appeared most credit constrained: $57 \%$ reported that they would be extremely unlikely to receive credit. Two additional variables characterize farm locations: altitude of the dwelling unit and travel time to agricultural input markets.

\section{Adoption of drought tolerant maize}

\subsection{Demand for DT maize varieties}

One way to gauge demand for DT maize seed is through farmers' perceptions of drought risk. If they perceive risk as minimal, demand is unlikely to be high. For the surveys, drought was defined as cessation of rainfall during a critical period of the growing season. When farmers were asked, "How many times in the last 10 years was your household negatively affected by drought or dry spells during the rainy season?", few of the sampled farmers reported no droughts (Fig. 1). The most common responses were that droughts occurred during 1-3 of the last 10 years, with Zimbabwean farmers reporting the largest number of recent droughts, on average.

Survey respondents were asked to list the top three characteristics considered in choosing a maize variety. In all countries, except Zambia, the maize traits mentioned most frequently were grain yield, drought tolerance, and early maturity (Table 1). In Zambia, grain yield, grain size, and early maturity were most important. Farmers were also asked if they would like to grow DT maize the following year. The responses were consistent across countries, ranging from 97 to $99 \%$ of farmers responding "yes" to the question.

\subsection{Current levels of cultivation of DT and other maize varieties}

The survey examined levels of cultivation of DT modern maize varieties, non-DT modern maize varieties, and local maize varieties. Modern maize is defined as hybrid, recycled hybrid, or open-pollinated varieties (OPVs), all resulting from scientific breeding. Non-DT modern maize was bred for traits other than drought tolerance (e.g., yield, disease resistance). Local maize varieties are the product of centuries of selection by farmers and the natural environment. Respondents reported the name of the maize varieties grown, which were categorized based on information from maize breeders at CIMMYT and Ministries of Agriculture.

In all of the countries studied, except Malawi, most maize plots were cultivated in a non-DT modern maize variety during 2012/13 (Table 1). DT varieties had lower uptake than non-DT modern maize in most of the study countries, which is not surprising, considering that breeding for drought tolerance only became prominent in 2007, when the DTMA project was initiated. Malawi had the highest percentage of maize plots cultivated in DT maize at $61 \%$, at least 


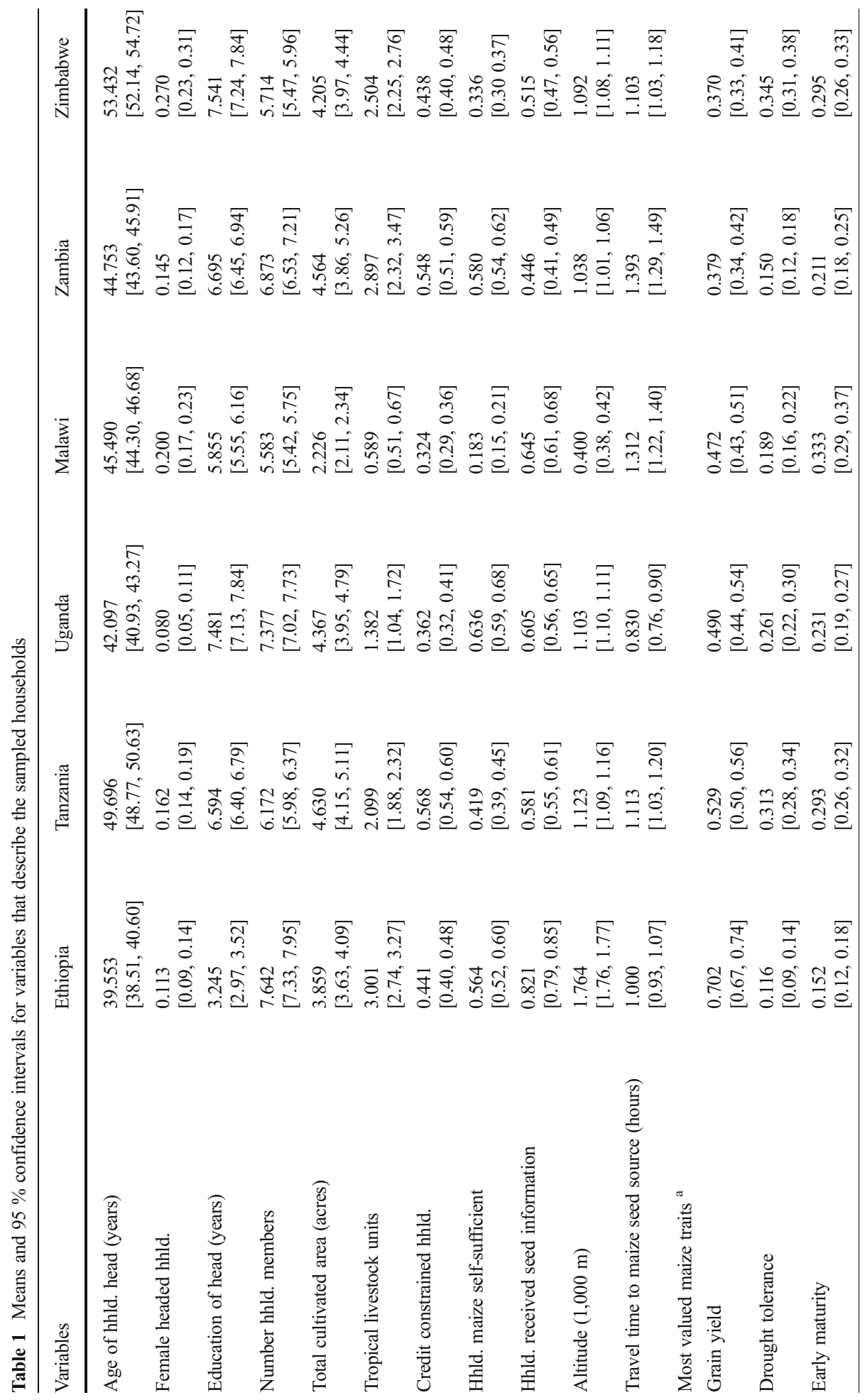




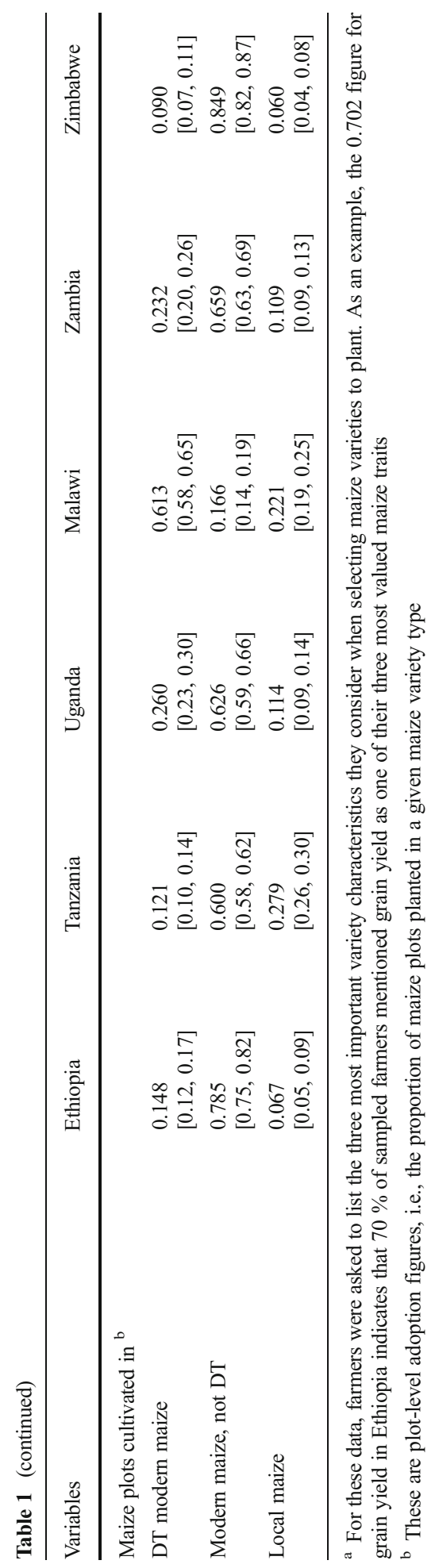




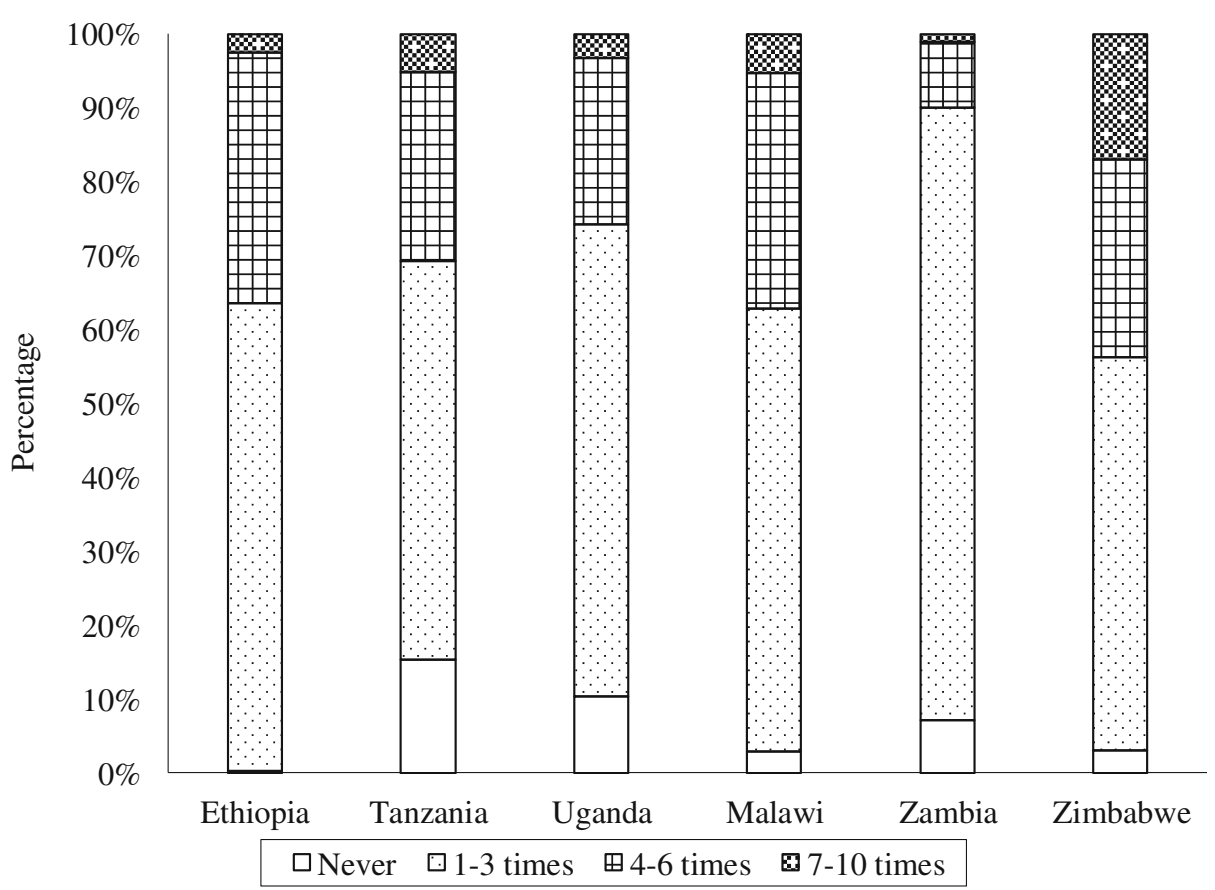

Fig. 1 Farmer perceptions of drought frequency in the last 10 years (2003-2013), by sampled country

partly owing to the country's Farm Input Subsidy Program (FISP) which has increased access to and promoted modern maize seed including DT maize varieties. The rate in the other five countries ranged from 9 to $26 \%$.

Local maize varieties were not widely grown, except in Tanzania and Malawi, where, respectively, 28 and $22 \%$ of sampled maize plots were planted in local maize, as part of a portfolio of local and modern varieties. In contrast, farmers in Ethiopia and Zimbabwe almost exclusively grew modern maize.

\subsection{Modeling the determinants of DT maize adoption}

We estimate a multinomial logit (MNL) model where the dependent variable is categorical, indicating the type of maize grown $(M)$ by a farmer on a farm plot: local maize, non-DT modern maize, or DT modern maize. Equation 1 describes the relationship between maize type $M$ and a set of explanatory variables expected to be influential, based on the literature on adoption of agricultural technology in low-income settings (Doss 2006; Feder et al. 1985; Foster and Rosenzweig 2010). This literature indicates that major determinants of adoption include trait preferences, financial and non-financial returns to adoption, farm size, tenure security, risk aversion, education, credit availability, access to extension services, and market access.

$$
M=\alpha_{0}+\alpha_{1} T+\alpha_{2} I+\alpha_{3} H+\alpha_{4} L+\alpha_{5} C+\varepsilon
$$

The first set of explanatory variables denoted vector $T$ are three dummy variables having value of 1 if the respondent stated that grain yield, drought tolerance, or early maturity is a 
Table 2 Multinomial logit results for the determinants of cultivation of DT modern maize, non-DT modern maize, and local maize

\begin{tabular}{|c|c|c|c|c|c|c|}
\hline & \multicolumn{2}{|c|}{ DT modern maize } & \multicolumn{2}{|c|}{ Non-DT modern maize } & \multicolumn{2}{|c|}{ Local maize } \\
\hline & $\begin{array}{l}\text { Marginal } \\
\text { Effect }^{a, b}\end{array}$ & $z$-value ${ }^{\mathrm{c}}$ & $\begin{array}{l}\text { Marginal } \\
\text { Effect }\end{array}$ & $z$-value & $\begin{array}{l}\text { Marginal } \\
\text { Effect }\end{array}$ & $z$-value \\
\hline Grain yield is a valued maize trait & ${ }^{*} 0.024$ & 2.14 & -0.013 & -1.05 & -0.011 & -1.08 \\
\hline Drought tolerance is a valued maize trait & ${ }^{*} 0.037$ & 3.07 & -0.009 & -0.66 & * -0.028 & -2.56 \\
\hline Early maturity is a valued maize trait & ${ }^{*} 0.031$ & 2.68 & ${ }^{*}-0.027$ & -2.02 & -0.004 & -0.35 \\
\hline Age of hhld. head (years) & 0.0002 & 0.60 & ${ }^{*}-0.001$ & -2.37 & ${ }^{*} 0.001$ & 2.54 \\
\hline Female headed hhld. & -0.001 & -0.07 & -0.007 & -0.41 & 0.008 & 0.63 \\
\hline Education of head (years) & ${ }^{*} 0.003$ & 1.96 & 0.003 & 1.33 & * -0.006 & -3.66 \\
\hline Number hhld. members & -0.001 & -0.71 & ${ }^{*} 0.005$ & 2.61 & * -0.004 & -2.30 \\
\hline Credit constrainted hhld. & -0.001 & -0.12 & * -0.025 & -2.07 & * 0.027 & 2.73 \\
\hline Total cultivated area (acres) & ${ }^{*} 0.006$ & 3.32 & -0.004 & -1.80 & -0.002 & -0.91 \\
\hline Tropical livestock units (TLU) & 0.001 & 0.40 & 0.001 & 0.36 & -0.002 & -0.69 \\
\hline Hhld. received information on maize seed & ${ }^{*} 0.029$ & 2.55 & 0.010 & 0.80 & ${ }^{*}-0.040$ & -3.99 \\
\hline Travel time to maize seed source (hours) & -0.003 & -0.62 & -0.004 & -0.81 & 0.008 & 1.87 \\
\hline Altitude of dwelling unit $(1,000 \mathrm{~m})$ & ${ }^{*}-0.135$ & -7.62 & ${ }^{*} 0.104$ & 5.68 & ${ }^{*} 0.031$ & 2.43 \\
\hline Ethiopia & * -0.148 & -4.74 & ${ }^{*} 0.402$ & 11.50 & * -0.254 & -8.83 \\
\hline Tanzania & * -0.325 & -18.59 & ${ }^{*} 0.347$ & 15.78 & ${ }^{*}-0.022$ & -1.38 \\
\hline Uganda & ${ }^{*}-0.163$ & -7.82 & ${ }^{*} 0.321$ & 11.98 & * -0.159 & -6.87 \\
\hline Zambia & ${ }^{*}-0.178$ & -8.97 & ${ }^{*} 0.354$ & 13.93 & ${ }^{*}-0.176$ & -8.07 \\
\hline Zimbabwe & ${ }^{*}-0.332$ & -14.64 & ${ }^{*} 0.572$ & 23.16 & ${ }^{*}-0.240$ & -11.04 \\
\hline $\begin{array}{l}\text { Number of observations } \\
\text { (maize plots) }\end{array}$ & & & & & & 5,140 \\
\hline Pseudo R-squared & & & & & & 0.15 \\
\hline Correctly classified (\%) & & & & & & 67.55 \\
\hline
\end{tabular}

a. Marginal effects are reported because coefficients can be difficult to interpret for the MNL model, given the need to compare to a base outcome

b. * indicates statistical significance at the 0.05 probability level or better

c. The $z$-values in the table are based on robust standard errors adjusted for clustering on household, to account for possible non-independence of maize plots within households

main variety attribute considered when selecting maize variety to plant, and 0 otherwise. These traits are chosen, based on their importance to farmers (Table 1), and because they are the main traits for which DT maize varieties have been bred.

Vector $I$ denotes characteristics of the household head: age, sex, and educational attainment. Household-level factors, $H$, hypothesized to influence adoption of DT maize include labor supply (number of household members); agricultural resources (total cultivated area and TLU); access to credit to purchase maize inputs; and access to information about new seeds from government agricultural extension officers, other farmers, electronic media, and other sources. Households are considered credit-constrained, if they stated it was extremely unlikely they would be able to borrow money from any source for the purchase of fertilizer, seed, and other inputs for maize production.

Locational factors, $L$, include altitude of the dwelling unit, which reflects growing conditions, and market access, represented as time to the nearest agricultural market. Finally, binary 


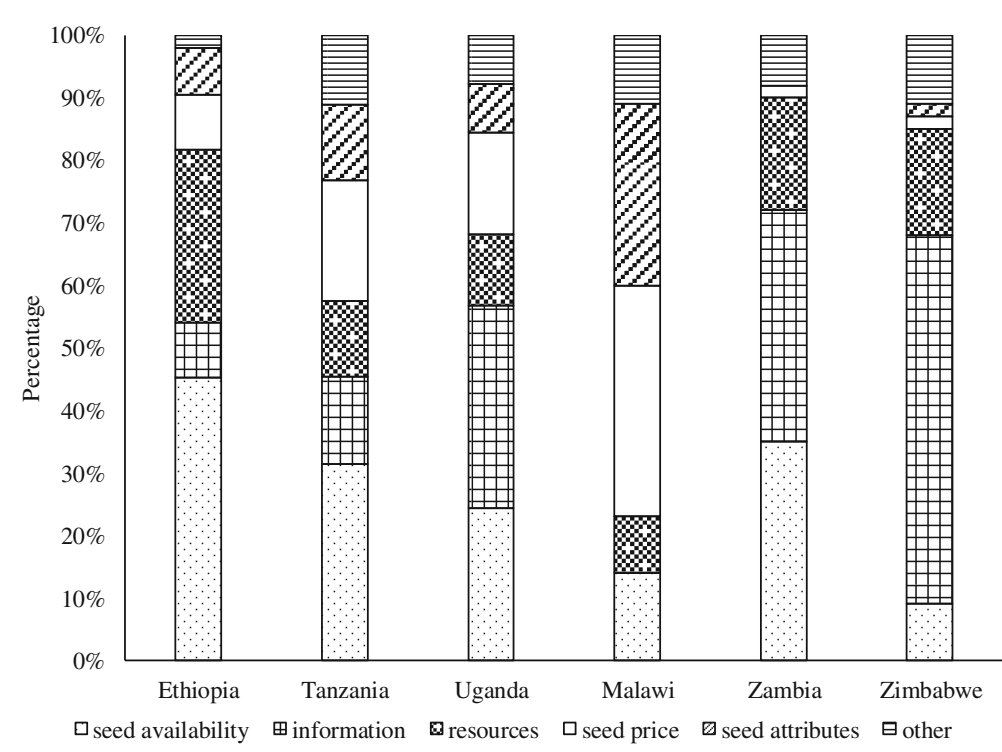

Fig. 2 Main barriers to adoption of DT maize, by sampled country. Farmers were asked "Why have you not tried growing a DT maize variety?" Farmers were allowed up to two responses, but most gave a single response. We use only the first mentioned response in calculating the percentages in the figure

variables for each country, $C$, except Malawi (the reference country) are included to control for socio-economic, political, and agro-ecological influences on farmers' decisions.

\subsection{Results on the determinants of DT maize adoption}

This section reports the MNL model results (Table 2) complemented by Fig. 2, which presents the most common answers to the question "Why have you not tried growing DT maize?" Results of the MNL model show that farmers who highly value grain yield, drought tolerance, and early maturity were more likely to grow DT maize varieties. These results are as expected, but they do not reveal that a sizable number of farmers said they have not tried growing the new DT maize varieties due to concerns about unfavorable attributes (see Fig. 2). In Tanzania, for example, some farmers were unwilling to try the DT maize varieties as they perceived them as low yielding, late maturing, and labor increasing. In Malawi, farmers complained of poor storability, i.e., they were concerned that DT maize varieties are prone to attack by storage pests, like weevils.

MNL model results (Table 2) show that compared with younger heads, older household heads were more likely to grow local maize and less likely to grow non-DT modern maize, probably reflecting reduced willingness of older farmers to give up familiar production practices. Households headed by a more educated individual were more likely to grow DT maize and less likely to grow local maize, suggesting educated individuals process information about new technologies more quickly and effectively (Foster and Rosenzweig 2010). However, there was no association between education level and the cultivation of non-DT modern maize.

Labor availability was a significant, positive factor in use of non-DT modern maize varieties. Cultivation of modern maize requires more farm labor during the peak agricultural 
season, because it is typically associated with a more intensive plant arrangement and fertilizer application than local maize. Thus, although labor was not found associated with early adoption of DT maize, sustained cultivation of DT maize might be difficult for households with limited labor, given that African labor markets often fail or function poorly.

Farmers who reported constrained credit were less likely to grow non-DT modern maize and more likely to cultivate local maize varieties, consistent with previous reports of links between credit access and adoption of agricultural technology (Croppenstedt et al. 2003). While the credit variable was not significantly associated with cultivation of DT maize, farm size, a key indicator of capacity to earn agricultural income and thus a useful proxy for access to cash, was an important determinant of DT maize cultivation.

Figure 2 reveals that lack of resources (labor, land, and cash) and high seed price were major reasons farmers had not tried growing the new DT maize varieties. For the case of land and cash availability, the Fig. 2 findings are consistent with the MNL model results. In Ethiopia, nearly one-third of farmers reported that lack of resources, especially money, prevented them from trying DT maize. High seed price was a commonly mentioned constraint in Malawi, Tanzania, and Uganda. Because many Tanzanian and Malawian farmers grow local maize, the switch to DT maize would entail a substantial increase in seed cost.

The MNL results indicate that households that received information on modern maize seed were more likely to grow DT modern maize and less likely to grow local maize. Figure 2, reveals the countries in which lack of information on DT maize was particularly problematic: Zambia and Zimbabwe. Table 2 shows no significant association between information receipt and cultivation of non-DT modern maize, perhaps indicative of a saturation of opportunities to learn about these modern varieties, many of which have been available for many years and thereby widely known by farmers (Fisher and Snapp 2014).

Altitude of the dwelling unit was negatively associated with adoption of DT maize, and positively associated with non-DT modern maize. Evapotranspiration and, therefore, moisture stress tend to be higher at lower elevations, possibly motivating low-altitude farmers to try DT varieties. Poor market access increases production costs and reduces profits, and therefore, is expected to result in reduced adoption of new agricultural technologies. The marginal effects for the time to maize seed source variable are of the expected signs in Table 2, but not statistically significant $(p<0.05)$. Figure 2 shows that seed availability constrained adoption of DT maize seed, especially in Ethiopia; but seed availability was less problematic in Malawi and Zimbabwe. Finally, the dummy variables for country are statistically significant and negatively associated with adoption of DT maize, indicating that country-level factors are important, and that Malawi is performing relatively well in disseminating DT maize to farmers.

\section{Discussion and conclusions}

Adoption of DT maize varieties varied widely among the six countries included in this study. Malawi had the highest rate, undoubtedly related to its large-scale Farm Input Subsidy Program (FISP). FISP, implemented since 2005/06, targets about $50 \%$ of farmers in the country to receive subsidized fertilizer for maize production, with additional vouchers for tobacco fertilizers and free modern maize seed (Lunduka et al. 2013). One study found that between 69 and $82 \%$ of sampled farmers that received a FISP voucher for maize seed redeemed their coupon for a DT maize variety (Holden and Fisher 2015). 
Uganda had the next highest rate of DT maize adoption, reflecting strong dissemination efforts by seed companies and agricultural extension. Early misunderstanding on the part of seed companies, agro-dealers, and agricultural extension agents, that DT varieties were meant only for marginal areas, slowed adoption in some countries. In particular, the national program in Ethiopia originally concentrated only in the central rift valley. Since 2012, however, DT maize has been promoted across the country's major growing areas.

Results of this study show that major barriers to adoption of DT maize include unavailability of improved seed, inadequate information, lack of resources, high seed price, and farmers' perceptions of variety attributes (Table 2 and Fig. 2). Differences in the main adoption constraints among countries (Fig. 2) are revealing. The key constraints are unavailability of improved seed and lack of resources in Ethiopia; unavailability and unaffordability of seed in Tanzania; unavailability of seed and inadequate information in Uganda; high seed price and storability in Malawi; inadequate information and unavailability of seed in Zambia; and inadequate information in Zimbabwe. Thus, specific combinations of supply-side (e.g., ensuring seed availability in local markets) and demand-side (e.g., ensuring farmer awareness of DT seed) solutions to low adoption of DT maize seed need to be sought for specific countries.

Our results have implications for policies that will enhance adoption of DT maize and increase resilience of smallholder farmers to drought in SSA. First, the supply of seed to local markets must be adequate to allow farmers to buy, experiment with, and learn about DT maize. Second, to make seed more accessible to farmers with limited cash or credit (another major barrier), seed companies and agro-dealers should consider selling DT maize seed in affordable micro-packs (1 or $2 \mathrm{~kg}$ ). Finally, enhanced adoption depends on enhanced awareness, which could be achieved through demonstration plots, field days, and distribution of print and electronic promotional materials. Lack or inaccuracy of information was a chief barrier to adoption across study countries. Many farmers had not heard of the new DT varieties, were unaware that they have high yields, or had concerns about seed attributes. It will also be important to investigate the accuracy of perceived unfavorable attributes. If the perceptions are accurate, maize breeders need to be informed. Whereas misperceptions about unfavorable seed attributes should be resolved by agricultural extension.

Acknowledgments This work was done while the lead author worked for the International Maize and Wheat Improvement Center (CIMMYT), on the Drought Tolerant Maize for Africa (DTMA) project, funded by the Bill \& Melinda Gates Foundation. The authors wish to thank Girma T. Kassie, Deborah Maleni, William Ekere, Mekonnen Sime, Samson Katengeza, Bernadette Chimai, and Shamiso Chikobvu for collaboration on the design and implementation of the surveys in Ethiopia, Uganda, Malawi, Zambia, and Zimbabwe. Many thanks are due to our respondents at the study sites.

Open Access This article is distributed under the terms of the Creative Commons Attribution 4.0 International License (http://creativecommons.org/licenses/by/4.0/), which permits unrestricted use, distribution, and reproduction in any medium, provided you give appropriate credit to the original author(s) and the source, provide a link to the Creative Commons license, and indicate if changes were made.

\section{References}

Alene AD, Menkir A, Ajala SO, Badu-Apraku B, Olanrewaju AS, Manyong VM, Ndiaye A (2009) The economic and poverty impacts of maize research in West and Central Africa. Agr Econ 40: $535-550$

Barbier B, Yacouba H, Karambiri H, Zoromé M, Somé B (2009) Human vulnerability to climate variability in the Sahel: Farmers' adaptation strategies in Northern Burkina Faso. Environ Management 43:790-803 
Bele MY, Sonwa DJ, Tiani AM (2014) Local communities vulnerability to climate change and adaptation strategies in Bukavu in DR Congo. J Env Dev 23(3):331-357

Brooks S (2014) Enabling adaptation? Lessons from the new 'Green Revolution' in Malawi and Kenya. Clim Chang 122:15-26

Bryan E, Deressa TT, Gbetibouo GA, Ringler C (2009) Adaptation to climate change in Ethiopia and South Africa: options and constraints. Environ Sci Policy 12:413-426

Bryan E, Ringler C, Okoba B, Roncoli C, Silvestri S, Herrero M (2013) Adapting agriculture to climate change in Kenya: household strategies and determinants. J Environ Manage 114:26-35

Burke M, Lobell D (2010) Food security and adaptation to climate change: What do we know? In Lobell D, Burke M (eds.) Climate Change and Food Security http://link.springer.com/book/10.1007\%2F978-90-4812953-9

Cairns JE, Hellin J, Sonder K, Araus JL, MacRobert JF, Thierfelder C, Prasanna BM (2013) Adapting maize production to climate change in sub-Saharan Africa. Food Sec 5(3):345-360

Cavatassi R, Lipper L, Narloch U (2011) Modern variety adoption and risk management in drought prone areas: insights from the sorghum farmers of eastern Ethiopia. Agr Econ 42:279-292

CIMMYT (2013) The Drought Tolerant Maize for Africa project. DTMA Brief, September http://dtma.cimmyt. org/index.php/about/background

CIMMYT (2014) DT Maize. A Quarterly Bulletin of the Drought Tolerant Maize for Africa Project 3(4) December 2014. http://dtma.cimmyt.org/index.php/component/content/article/110-news-articles/180-dtmamoves-to-the-next-level-welcoming-dtmass CIMMYT, Nairobi

Codjoe SNA, Atidoh LK, Virginia B (2012) Gender and occupational perspectives on adaptation to climate extremes in the Afram Plains of Ghana. Clim Chang 110(1-2):431-454

Croppenstedt A, Demeke M, Meschi MM (2003) Technology adoption in the presence of constraints: the case of fertilizer demand in Ethiopia. Rev Dev Econ 7:58-70

Deressa TT, Hassan RM, Ringler C, Alemu T, Yusuf M (2009) Determinants of farmers' choice of adaptation methods to climate change in the Nile Basin of Ethiopia. Glob Environ Change 19(2):248-255

Di Falco S, Bezabih M, Yesuf M (2010) Seeds for livelihood: crop biodiversity and food production in Ethiopia. Ecol Econ 69:1695-1702

Doss CR (2006) Analyzing technology adoption using microstudies: limitations, challenges, and opportunities for improvement. Agr Econ 34:207-219

Feder G, Just RE, Zilberman D (1985) Adoption of agricultural innovations in developing countries: a survey. Econ Dev Cult Change 33:255-297

Fisher M, Snapp S (2014) Smallholder farmers' perceptions of drought risk and adoption of modern maize in Southern Malawi. Exp Agr 50(4):533-548

Foster AD, Rosenzweig MR (2010) Microeconomics of technology adoption. Annu Rev Econ 2:395-424

Fosu-Mensah BY, Vlek PLG, MacCarthy DS (2012) Farmers' perception and adaptation to climate change: a case study of Sekyedumase district in Ghana. Environ Dev Sustain 14:495-505

Gbetibouo GA, Hassan RM, Ringler C (2010) Modelling farmers' adaptation strategies for climate change and variability: the case of the Limpopo Basin, South Africa. Agrekon 49(2):217-234

Hassan R, Nhemachena C (2008) Determinants of African farmers' strategies for adapting to climate change: Multinomial choice analysis. AfJARE 2(1)

Hisali E, Birungi P, Buyinza F (2011) Adaptation to climate change in Uganda: evidence from micro level data. Glob Environ Chang 21:1245-1261

Holden ST, Fisher M (2015) Can adoption of improved maize varieties help smallholder farmers adapt to drought? Evidence from Malawi. CLTS Working Paper 1, 2015. Centre for Land Tenure Studies, Norwegian University of Life Sciences, Aas

Intergovernmental Panel on Climate Change (IPCC) (2014) Climate change 2014: impacts, adaptation, and vulnerability. Part B: regional aspects. Contribution of working group II to the fifth assessment report of the intergovernmental panel on climate change. Cambridge University Press, Cambridge, p 688

Jahnke HE (1982) Livestock production systems and livestock development in tropical Africa. Kieler Wissenschaftsverlag Vauk, Kiel

Jarvis A, Ramirez-Villegas J, Herrera Campo BV, Navarro-Racines C (2012) Is cassava the answer to African climate change adaptation? Trop Plant Biol 5(1):9-29

Karaba A, Dixit S, Greco R, Aharoni A, Trijatmiko K, Marsch-Martinez N, Krishnan A, Nataraja K, Udayakumar M, Pereira A (2007) Improvement of water use efficiency in rice by expression of hardy, an arabidopsis drought and salt tolerance gene. Proc Natl Acad Sci U S A 104(39):15270

Kijima Y, Otsuka K, Sserunkuuma D (2011) An inquiry into constraints on a green revolution in sub-Saharan Africa: the case of NERICA rice in Uganda. World Dev 39(1):77-86

Kurukulasuriya P, Mendelsohn R (2006) Crop selection: adapting to climate change in Africa. Centre for Environmental Economics and Policy in Africa, University of Pretoria, Pretoria 
La Rovere R, Abdoulaye T, Kostandini G, Guo Z, Mwangi W, MacRobert J, Dixon J (2014) Economic, production and poverty impacts of investing in maize tolerant to drought in Africa. $\mathrm{J}$ Dev Areas $48(1)$ : $199-225$

Li YP, Ye W, Wang M, Yan X (2009) Climate change and drought: a risk assessment of crop-yield impacts. Clim Res 39:31-46

Lunduka R, Ricker-Gilbert J, Fisher M (2013) What are the farm-level impacts of Malawi's Farm input subsidy program? Agr Econ 44(6):563-579

Lybbert TJ, Sumner DA (2012) Agricultural technologies for climate change in developing countries: policy options for innovation and technology diffusion. Food Policy 37:114-123

Mertz O, Mbow C, Reenberg A (2009) Farmers' perceptions of climate change and agricultural adaptation strategies in Rural Sahel. Environ Manage 43:804-816

Orlove B, Roncoli C, Kabugo M, Majugu A (2010) Indigenous climate knowledge in southern Uganda: the multiple components of a dynamic regional system. Clim Chang 100:243-265

Reason CJC, Hachigonta S, Phaladi RF (2005) Interannual variability in rainy season characteristics over the Limpopo region of Southern Africa. Int J Climatol 25:1835-1853

Shiferaw B, Tesfaye K, Kassie M, Abate T, Prasanna BM, Menkir A (2014) Managing vulnerability to drought and enhancing livelihood resilience in sub-Saharan Africa: technological, institutional, and policy options. Weather Climate Extremes 3:67-79

Smale M, Jayne TS (2003) Maize breeding in East and Southern Africa, 1900-2000. International Food Policy Research Institute http://ideas.repec.org/p/fpr/2020br/1204.html. Accessed 18 December 2008

Smale M, Byerlee D, Jayne T (2011) Maize revolutions in sub-Saharan Africa. World bank policy research working paper 5659, May. The World Bank, Washington

Sofoluwe NA, Tijani AA, Baruwa OI (2011) Farmers' perception and adaptation to climate change in Osun State, Nigeria. Afr J Agric Res 6(20):4789-4794

Tambo JA, Abdoulaye T (2013) Smallholder farmers' perceptions of and adaptations to climate change in the Nigerian savanna. Reg Environ Change 13:375-388

Thomas DSG, Twyman C, Osbahr H, Hewitson B (2007) Adaptation to climate change and variability: farmer responses to intra-seasonal precipitation trends in South Africa. Clim Chang 83:301-322

Westengen OT, Brysting AK (2014) Crop adaptation to climate change in the semi-arid zone in Tanzania: the role of genetic resources and seed systems. Agric Food Secur 3:3

You L, Ringler C, Wood-Sichra U, Robertson R, Wood S, Zhu T, Nelson G, Guo Z, Sun Y (2011) What is the irrigation potential for Africa? A combined biophysical and socioeconomic approach. Food Policy 36:770782 